Published in final edited form as:

J Diabetes Complications. 2016 March ; 30(2): 262-268. doi:10.1016/j.jdiacomp.2015.11.025.

\title{
Analysis of Advanced Glycation End Products in the DHS Mind Study
}

\author{
Jeremy N. Adams ${ }^{a},{ }^{,}$, Susan E. Martelle ${ }^{a},{ }^{*}$, Laura M. Raffield ${ }^{a}$, Barry I. Freedman ${ }^{b}$, Carl D. \\ Langefeld $^{\mathrm{c}}$, Fang-Chi Hsu ${ }^{\mathrm{c}}$, Joseph A. Maldjian ${ }^{\mathrm{d}}$, Jeff D. Williamson ${ }^{\mathrm{e}}$, Christina E. \\ Hugenschmidt ${ }^{e}$, J. Jeffery Carr ${ }^{a}$, Amanda J. Cox ${ }^{\dagger}$, and Donald W. Bowden ${ }^{a}$ \\ ${ }^{a}$ Center for Genomics and Personalized Medicine Research, Wake Forest School of Medicine, \\ Winston - Salem, NC, USA \\ bepartment of Internal Medicine, Nephrology, Wake Forest School of Medicine, Winston - \\ Salem, NC, USA \\ 'Department of Biostatistical Sciences, Wake Forest University Health Sciences, Winston Salem, \\ North Carolina \\ ${ }^{\mathrm{d}}$ Radiologic Sciences and Advanced NeuroScience Imaging (ANSIR) Laboratory, Wake Forest \\ School of Medicine, Winston-Salem, NC, USA \\ eDepartment of Internal Medicine, Gerontology and Geriatric Medicine, Wake Forest School of \\ Medicine, Winston - Salem, NC, USA \\ ${ }^{f}$ Molecular Basis of Disease, Griffith University, Southport, QLD, Australia
}

\section{Abstract}

\begin{abstract}
Aims-Human studies of links between advanced glycation end-products (AGEs) and disease phenotypes are less common than studies of animal and cell models. Here, we examined the association of total AGEs with diabetes risk factors in a predominately type 2 diabetes (T2D) affected cohort.
\end{abstract}

Methods-AGEs were measured using an enzyme linked immunosorbant assay in 816 individuals from the DHS Mind Study ( $\mathrm{n}=709$ T2D affected), and association analyses were completed.

Results-Total AGEs were associated with estimated glomerular filtration rate $(\mathrm{p}=0.0054 ; \beta=$ $-0.1291)$ and coronary artery calcification $(\mathrm{p}=0.0352 ; \beta=1.1489)$ in the entire cohort. No significant associations were observed when individuals with T2D were analyzed separately. In individuals without T2D, increased circulating AGEs were associated with increased BMI ( $\mathrm{p}=$

Corresponding Author: Donald W. Bowden, Ph.D., Wake Forest University School of Medicine, Medical Center Blvd., WinstonSalem, NC 27157, USA, Telephone: 336-713-7507, FAX: 336-713-7566, dbowden@ wakehealth.edu.

Co-first authors

Conflicts of interest: none

Publisher's Disclaimer: This is a PDF file of an unedited manuscript that has been accepted for publication. As a service to our customers we are providing this early version of the manuscript. The manuscript will undergo copyediting, typesetting, and review of the resulting proof before it is published in its final citable form. Please note that during the production process errors may be discovered which could affect the content, and all legal disclaimers that apply to the journal pertain. 
$0.02, \beta=0.138)$, low density lipoproteins $(\mathrm{p}=0.046, \beta=17.07)$ and triglycerides $(\mathrm{p}=0.0004, \beta=$ $0.125)$, and decreased carotid artery calcification $(\mathrm{p}=0.0004, \beta=-1.2632)$ and estimated glomerular filtration rate $(\mathrm{p}=0.0018, \beta=-0.1405)$. Strong trends were also observed for an association between AGEs and poorer cognitive performance on the digit symbol substitution test $(\mathrm{p}=0.046, \beta=-6.64)$ and decreased grey matter volume $(\mathrm{p}=0.037, \beta=-14.87)$.

Conclusions-AGEs may play an important role in a number of phenotypes and diseases, although not necessarily in interindividual variation in people with T2D. Further evaluation of specific AGE molecules may shed more light on these relationships.

\section{Keywords}

Advanced glycation end products; cardiovascular disease; cognition; grey matter volume; neuroimaging; type 2 diabetes

\section{Introduction}

Advanced glycation end products (AGEs) are a diverse, heterogenous class of molecules formed through the non-enzymatic glycation and oxidation of proteins, lipids, and nucleic acids (Nowotny et al., 2015). AGEs - which accumulate with age and are also introduced by diet - have negative consequences on free radical production, proinflammatory processes, and the immune system (Singh et al., 2014). AGEs are a major pathway for diabetic complications including cognitive deficits (Coker and Wagenknecht, 2011, Spauwen et al., 2015, Yaffe et al., 2011, Yaffe et al., 2012), retinopathy (Singh et al., 2001), neuropathy (Juranek et al., 2013), neuropathology (Moran et al., 2015), and kidney disease (Beisswenger et al., 2013, Leurs and Lindholm, 2013, Thomas et al., 2015). In diabetes, for example, activation of the receptor for AGE (RAGE) reduces tissue protein degradation and can lead to impaired tissue remodeling (Piarulli et al., 2012). Through accumulation on vessel walls, AGEs have been implicated as playing a large role in the formation and progression of arterial atherosclerosis (Kiuchi et al., 2001). Additionally, in T2D-affected individuals, AGEs have been associated with cardiovascular and coronary mortality (Kilhovd et al., 1999), ischemic heart disease (Kaled A. Ahmed, 2007), and severity of coronary artery atherosclerosis (Hegab et al., 2012).

Significantly, most in-vivo studies investigating the deleterious effects of AGEs have been performed in animal models or cell lines. Furthermore, studies investigating AGEs in humans, in general, have relatively low numbers of participants (e.g. (Juranek et al., 2013, Kellow and Savige, 2013)). The purpose of the current study is to investigate the association of AGEs with a broad range of traits encompassing T2D comorbidities, including measures of kidney function, cognitive decline, brain structure, and subclinical cardiovascular disease available in an extensively studied community-based cohort - the Diabetes Heart Study (DHS), and the DHS Mind, an ancillary study measuring cognition and brain imaging metrics. We hypothesized that circulating levels of AGEs are associated with macrovascular and other complications in T2D. Specifically, we tested previously documented relationships, such as between total AGEs and cardiovascular complications (Aso et al., 2000, Hanssen et al., 2015, B. K. Kilhovd, 2007) as well as investigating novel relationships with measures of cognitive functioning and neuroanatomy. 


\section{Subjects}

The DHS Mind study is an ancillary study to the DHS with the purpose of investigating the relationships between cognitive function, brain imaging, and vascular disease in T2D.

Participants from the original DHS investigation were re-examined on average $6.7 \pm 1.6$ years after the initial visit. Participant examinations were conducted in the General Clinical Research Center of the Wake Forest Baptist Medical Center. The current AGE, cognitive, and brain image analyses are based on a subset of 504 participants returning from the baseline DHS exam with measured phenotypes from the DHS Mind study visit and 312 additional individuals recruited for the DHS Mind study. For these analyses, level of educational attainment was classified as less than high school, high school, or greater than high-school based on self-report by participants.

Briefly, the DHS includes siblings concordant for T2D but without advanced renal insufficiency. When possible, unaffected siblings were also recruited. Subjects were recruited from western North Carolina between 1998 and 2005. T2D was clinically defined as diabetes developing after the age of 35 years and initially treated with oral agents and/or diet and exercise, in the absence of historical evidence of ketoacidosis. Diagnoses were confirmed by measurement of fasting blood glucose and glycosylated hemoglobin $\left(\mathrm{HbA}_{1 \mathrm{c}}\right)$. Confirmation of T2D status at the DHS Mind visit, not the baseline visit, was used in the present analysis. Measurements of CVD risk factors were obtained during baseline exams. Examinations including interviews for medical history and health behaviors, anthropometric measures, resting blood pressure, electrocardiography, fasting blood sampling and spot urine collection were performed. Ascertainment and recruitment have been previously described in detail (Bowden et al., 2008, Bowden et al., 2010, Lange et al., 2002, Wagenknecht et al., 2001). Individuals reported a history of CVD based on prior events (angina, myocardial infarction, stroke) and/or interventions (coronary angiography, coronary artery bypass grafting, carotid endarterectomy). Coronary artery calcified plaque (CAC), carotid artery calcified plaque (CarCP) and infra-renal abdominal aortic calcified plaque (AACP) were measured using fast-gated helical CT scanning, and calcium scores calculated as previously described and reported as mass scores (Carr et al., 2005, Carr et al., 2000). Carotid intimamedia thickness (IMT) was measured by high-resolution B-mode ultrasonography with a 7.5-MHz transducer and a Biosound Esaote (AU5) ultrasonography machine (Biosound Esaote, Inc., Indianapolis, IN) as previously described (Lange et al., 2002). Study protocols were approved by the Institutional Review Board at Wake Forest School of Medicine and all study procedures were carried out in accordance with the Declaration of Helsinki. All participants provided written informed consent before participation.

\section{Methods and Materials}

\subsection{Neuroimaging}

Neuroimaging scans and metrics were performed at the DHS Mind visit as previously described (Raffield et al., 2014). Briefly, the MRI was performed on a 1.5-T EXCITE HD scanner with twin-speed gradients using a neurovascular head coil (GE Healthcare, Milwaukee, WI). Structural T1 images were segmented into grey matter (GM), white matter (WM), and cerebrospinal fluid (CSF), normalized to Montreal Neurologic Imaging (MNI) 
space, and modulated with the Jacobian determinants of the warping procedure using SPM8 (Ashburner and Friston, 2000) new segment procedure as implemented in the VBM8 toolbox (http://dbm.neuro.uni-jena.de/vbm.html). Intracranial volume (ICV) (GM+WM $+\mathrm{CSF}$ ), total brain volume (TBV) (GM+WM), grey matter volume (GMV) (GM), and white matter volume (WMV) (WM) were determined from the automated segmentation procedure using VBM8. Diffusion tensor was calculated using the Camino software package (www.camino.org.uk), converted to NIfTI with the Diffusion Tensor Imaging Toolkit (http://www.nitrc.org/projects/dtitk), and coregistered to T1 structural data with SPM8 to derive fractional anisotropy (FA) and mean diffusivity (MD). Cerebral blood flow (CBF) processing images were generated using a fully automated data processing pipeline as previously described (Maldjian et al., 2008). White matter lesion segmentation as performed using the lesion segmentation toolbox (Schmidt et al., 2012) and validated in the DHS cohort (Maldjian et al., 2013). Total white matter lesion volume (WMLV) was determined by summing the binary lesion maps and multiplying by the voxel volume.

\subsection{Cognitive Testing}

In the DHS Mind, participants were administered a battery of cognitive tests as described previously (Hugenschmidt et al., 2013). Briefly, these tests included the Digit Symbol Substitution Test (DSST) (Wechsler, 1981) in which performance was defined as the number of correct responses within $2 \mathrm{~min}$. The Controlled Oral Word Association Test (COWA) (Strauss et al., 2006, Benton et al., 1994) tested the metric of Phonemic Fluency by the sum of words generated for three different letters (F, A, S) while Semantic Fluency was measured as the sum of words generated for two different categories (kitchen, animals). The Stroop test (Houx et al., 1993) measured the response time difference between subtest 2 and subtest 3 with the number of errors from each subtest added to the time scores. The Rey Auditory-Verbal Learning Test (RAVLT) (Lezak et al., 2004) measured the sum of words remembered across the first 5 trials. Also included in the battery of tests was the Modified Mini-Mental State Examination (3MSE) (Teng and Chui, 1987).

\subsection{Advanced Glycation End Products}

Total serum AGEs were measured using a competitive enzyme linked immunosorbant assay (ELISA) (Lifeome Biolabs; Oceanside, CA) using serum from participants in the DHS-Mind visit. The ELISA was run according to the manufacturer's recommendations using previously frozen serum. The ELISA uses a monoclonal antibody that is specific to AGEs and has a minimum detectable dose of AGEs of $35.2 \mathrm{ng} / \mathrm{ml}$. Intra-assay and inter-assay precision was $2.0 \%$ and $22.5 \%$, respectively.

\subsection{Statistical Analysis}

All statistical analyses were run using SAS v. 9.3 (SAS Institute Inc. Cary, N.C.). Continuous variables were natural $\log$ transformed when necessary to normalize the distribution. A marginal model incorporating generalized estimating equations to account for the family structure was performed to regress each trait on the covariates. Model 1 was performed in all DHS participants; models were adjusted for age, gender, natural log transformed pulse pressure, diabetes medication use (insulin plus oral medications), smoking status (current, former, never), and T2D-affected status. An interaction term for 
T2D status and AGEs was also included for Model 1. Model 2 was performed only in individuals with T2D and was adjusted for age, gender, natural log transformed pulse pressure, diabetes medication, and smoking status. Model 3 was adjusted for the same covariates as Model 2 but was run in individuals unaffected by T2D. Association analyses with body mass index (BMI) and gender included affected status and the interaction term only. The association of AGEs with T2D status and T2D duration included age, gender, smoking, and natural log transformed pulse pressure as covariates. An additional covariate, cholesterol medication use, was also included for the blood lipid traits. For the analyses of the cognitive function traits, age, gender, T2D status, and education attainment level were included as covariates. Age, gender, T2D status, scanner, and education attainment level were used as covariates in the brain imaging traits; total intercranial volume was an additional covariate for analysis of grey and white matter. Due to the exploratory nature of the sub-group analysis, statistical significance was set at $\mathrm{p}<0.05$.

\section{Results}

\subsection{Demographics}

Demographics of the individuals included in this study are shown in Table 1 . The average age was 66 years old and just over half of the cohort was female (approximately 53\%). The individuals were on average overweight or obese with an average BMI of $32.6 \mathrm{~kg} / \mathrm{m}^{2}$. Approximately $87 \%$ of the individuals were affected by T2D with an average duration of 15.3 years. The DHS and DHS Mind participants have characteristics that are broadly representative of T2D-affected patients in the general population: older, relatively obese, and with significant risk factors and history of CVD and impaired kidney function.

\subsection{Associations with Anthropometric and Laboratory Traits}

We investigated potential associations of total AGEs with a variety of anthropometric and laboratory traits. Analyses were carried out in all subjects (T2D + unaffected), T2D-affected only, T2D-unaffected only (Table 2). We did not observe association of AGEs with any of the traits when the entire cohort was analyzed as a single sample. In addition, total AGEs were not different between individuals with $\mathrm{T} 2 \mathrm{D}\left(\mathrm{AGE}_{\mathrm{avg}}=41.1 \mathrm{ng} / \mathrm{ml}\right)$ and without T2D $\left(\mathrm{AGE}_{\mathrm{avg}}=39.2 \mathrm{ng} / \mathrm{ml}\right)(\mathrm{p}=0.44)$. AGEs were not associated with either T2D status $(\mathrm{p}=0.82)$, T2D duration ( $\mathrm{p}=0.0 .65)$, fasting glucose $(\mathrm{p}=0.0 .17)$, or $\mathrm{HbA}_{1 \mathrm{c}}(\mathrm{p}=0.55)$. No significant associations were observed in the T2D-affected subset. In the T2D unaffected subset, AGEs were positively significantly associated with BMI ( $\mathrm{p}=0.02)$, low density lipoprotein (LDL; $\mathrm{p}=0.046)$, and triglycerides $(\mathrm{p}=0.0004)$. We did not observe significant associations with any other traits including age, gender, smoking, high density lipoprotein (HDL), or T2D medication or statin use.

\subsection{Cardiovascular and Kidney Trait Associations}

Associations of AGEs with CVD and kidney disease were tested using subclinical measures of disease (Table 3). Heightened AGEs were significantly associated with CAC in model 1 $(\mathrm{p}=0.035, \beta=1.149)$, but not in the T2D only $(\mathrm{p}=0.68, \beta=0.101)$ or non-T2D $(\mathrm{p}=0.06 ; \beta$ $=1.183$ ) subsets. iln the non-T2D subset we observed associations between heightened 
AGEs and decreased CarCP $(\mathrm{p}=0.0004 ; \beta=-1.263)$. We did not observe any association with AACP or IMT.

We analyzed two traits representative of kidney function - estimated glomerular filtration rate (eGFR) and albumin to creatinine ratio (ACR). Decreased eGFR was found to be associated with increased AGE levels in the entire cohort $(\mathrm{p}=0.0054)$. Further analysis revealed that eGFR was significantly inversely associated with AGEs only in individuals without T2D ( $p=0.0018 ; \beta=-0.1405$ ). ACR was not found to be associated in the entire cohort or in either of the subsets ( $p=0.96$ all, $p=0.61 T 2 D, p=0.98$ non-T2D).

\subsection{Brain Imaging and Cognitive Function Associations}

In addition to CVD and kidney disease, we also investigated cognitive function and brain MRI measures (Table 4). Again, no significant associations were observed for the entire cohort or the subset with T2D. Increased AGEs were associated with lower scores on the digit symbol substitution test ( $\mathrm{p}=0.046 ; \beta=-6.64)$ in individuals without T2D. No other cognitive measures (tests for Phonemic or Semantic Fluency, 3MSE, the Stroop test, and the RAVLT) were significant in any of the subsets.

Similarly, only one of the brain MRI traits was associated with AGEs. Heightened AGEs were associated with decreased grey matter volume $(p=0.037 ; \beta=-14.871)$ in individuals without T2D. However, we did not see any other significant associations with WMV, TBV, WMLV, WMFA or GMFA, WMMD or GMMD, or CBF.

\section{Discussion}

The current study was a comprehensive examination of the role of AGEs in common comorbidities found in T2D. Several associations with a range of traits were observed in analysis of the non-T2D affected subjects. These traits included increased LDL, triglycerides and increased BMI (Table 2) as well as associations with CVD and kidney function traits such as increased CAC, increased CarCP, and decreased eGFR (Table 3). Next, we observed an association with Digit Symbol Substitution Task scores, suggesting a potential relationship of AGEs in processing speed and working memory, agreeing with a similar finding by Yaffe and colleagues (Yaffe et al., 2011) (Table 4). Lastly, AGEs were associated with GMV, supporting prior literature (Srikanth et al., 2013) and implicating AGEs as moderators in T2D-related brain atrophy (Moran et al., 2015) (Table 4). Most associations were found only in non-diabetic individuals which is consistent with some prior studies (Hanssen et al., 2013, Teichert et al., 2015, Scholtes et al., 2014, Yu et al., 2010). The most compelling observation that T2D status affected associations with AGEs was with eGFR.; eGFR was inversely associated with AGEs in the entire cohort (model 1), but was modified by affected status (interaction term $\mathrm{p}=0.03$ ) and further analysis (model 3) suggests the initial finding was driven by unaffected individuals.

Advanced glycation end products have a long history of association with a variety of traits and diseases. AGEs have been reported to be associated with traits including age (Jiang et al., 2012, Lopes-Virella et al., 2012), BMI, and waist to hip ratio (Amin et al., 2011), as well as gender (Jiang et al., 2012, B. K. Kilhovd, 2007) and a range of CVD risk factors 
including measures of blood pressure (Sourris et al., 2014), smoking (Fukushima et al., 2013), and LDL cholesterol (Lopes-Virella et al., 2012). However, the literature is conflicted. Part of the reason for this complication is there is no consistent method of detecting AGEs, internal standards, nor standardized unit of measurements that are universally accepted (Singh et al., 2001). Multiple studies have suggested there is no association between AGEs and blood pressure (Lopes-Virella et al., 2012, Fukushima et al., 2013). Lopes-Virella et al. also found no association between AGEs and BMI (LopesVirella et al., 2012). Moreover, associations with $\mathrm{HbA}_{1 \mathrm{c}}$ are equivocal. For example, Llauradó et al. and Turk et al. showed that AGEs were highly associated with $\mathrm{HbA}_{1 \mathrm{c}}$, while another study performed by de Vos et al. found that they were not associated (de Vos et al., 2014, Llaurado et al., 2014, Turk et al., 1998). One possible explanation for such a discrepancy between studies investigating measures of glucose metabolism could originate from diet-introduced AGEs, as plasma levels increase after dietary intake (Teichert et al., 2015). Future studies carefully documenting and analyzing dietary habits of cohorts in which AGEs are assessed may be warranted and in fact, at least one is underway (de Courten et al., 2015).

A second problem with the AGE associations stems from the heterogenous nature of AGEs. Multiple studies that have investigated two or more types of AGEs have found divergent results. Jiang et al. found that carboxymethyllysine (CML) levels were significantly different in patients on peritoneal dialysis as compared to those on hemodialysis, but saw no statistical difference in global AGE levels (Jiang et al., 2012). In a study investigating individuals with type 1 diabetes, with or without macroalbuminuria, van Eupen et al. found that CML and pentosidine levels were associated with macroalbuminuria and retinopathy while $\mathrm{N}^{\varepsilon}$-carboxyethyl lysine (CEL) and tetrahydropyrimidine levels were not (van Eupen et al., 2013). Beisswenger et al. found that CEL and CML levels were higher in individuals with enhanced progression of diabetic nephropathy, while other AGE measures were not different (2013). An additional study found different association patterns between CEL, CML, pentosidine, and AGE levels with CVD mortality and all-cause mortality (Nin et al., 2011). Finally, Kilhovd and colleagues showed an association of global serum AGEs with T2D and coronary heart disease affected status, but did not see this association with CML (Kilhovd et al., 1999). These results suggest divergent roles for different classes of AGEs, which is not surprising given the diverse structure, functions, and distribution in different cell types of the compounds (Goldin et al., 2006). Thus, findings in the present study are limited by the assay and future studies will need to employ measures of specific AGEs.

Lastly, although AGEs were only observed to be associated with phenotypes in nondiabetics, methodological limitations may have masked an association of AGEs within the T2D population. For instance, Okamoto et al observed that when microvascular endothelial cells cultured with AGEs were treated with statins, AGE-RAGE-elicited angiogenesis was blocked (Okamoto et al., 2002). This suggests that statins may act as an AGE inhibitor (Yamagishi et al., 2006) and may have had a protective effect in T2D individuals. However, the observation that statin use was not significantly associated with AGEs $(p=0.15)$ in the present study suggest that this was not a confounding factor. Additionally, several other therapies have the ability to reduce the accumulation of AGEs such as metformin and ACE 
inhibitors (Thomas et al., 2005). Importantly, all analyses adjusted for diabetic medication use. Secondly, similar proportions of T2D and non-diabetic individuals (21\% and $35 \%$, respectively) were currently prescribed ACE-inhibitors, thus associations with AGEs would have been similarly effected in both cohorts.

\subsection{Conclusions}

Advanced glycation end products have a complicated history of associations with a range of traits and diseases, most notably diabetes. This study adds to the increasing breadth of knowledge of AGEs and their function in human disease. However, a limitation to the current study is the separation of years between baseline DHS measures and the acquisition of AGEs and cognitive and neuroanatomical measures for participants returning from the original DHS study. Nonetheless, this study, in combination with prior literature, suggests that AGE associations with traits and diseases are complex, and the field would benefit from future investigations employing more sensitive and specific measures of a diverse range of AGEs.

\section{Acknowledgments}

This study was supported in part by the National Institutes of Health through R01 HL67348, R01 HL092301, R01 NS058700 (to DWB), F32 DK083214-01 (to CEH), and F31 AG044879 (to LMR). The authors thank the other investigators, the staff, and the Diabetes Heart Study participants for their valuable contributions.

\section{References}

AMIN MN, MOSA AA, EL-SHISHTAWY MM. Clinical study of advanced glycation end products in egyptian diabetic obese and non-obese patients. Int J Biomed Sci. 2011; 7:191-200. [PubMed: 23675236]

ASHBURNER J, FRISTON KJ. Voxel-based morphometry--the methods. Neuroimage. 2000; 11:80521. [PubMed: 10860804]

ASO Y, INUKAI T, TAYAMA K, TAKEMURA Y. Serum concentrations of advanced glycation endproducts are associated with the development of atherosclerosis as well as diabetic microangiopathy in patients with type 2 diabetes. Acta Diabetol. 2000; 37:87-92. [PubMed: 11194933]

KILHOVD BK, LEHTO AJS, RÖNNEMAA T, TORJESEN PA, HANSSEN KF, LAAKSO M. Increased serum levels of advanced glycation endproducts predict total, cardiovascular and coronary mortality in women with type 2 diabetes: a population-based 18 year follow-up study. Diabetologia. 2007; 50:1409-1417. [PubMed: 17479244]

BEISSWENGER PJ, HOWELL SK, RUSSELL GB, MILLER ME, RICH SS, MAUER M. Early progression of diabetic nephropathy correlates with methylglyoxal-derived advanced glycation end products. Diabetes Care. 2013; 36:3234-9. [PubMed: 23780945]

BENTON, AL.; HAMSHER, KDS.; SIVAN, AB. Multilingual Aphasia Examination. Iowa City, IA: AJA Associates; 1994.

BOWDEN DW, COX AJ, FREEDMAN BI, HUGENSCHIMDT CE, WAGENKNECHT LE, HERRINGTON D, AGARWAL S, REGISTER TC, MALDJIAN JA, NG MC, HSU FC, LANGEFELD CD, WILLIAMSON JD, CARR JJ. Review of the Diabetes Heart Study (DHS) family of studies: a comprehensively examined sample for genetic and epidemiological studies of type 2 diabetes and its complications. Rev Diabet Stud. 2010; 7:188-201. [PubMed: 21409311]

BOWDEN DW, LEHTINEN AB, ZIEGLER JT, RUDOCK ME, XU J, WAGENKNECHT LE, HERRINGTON DM, RICH SS, FREEDMAN BI, CARR JJ, LANGEFELD CD. Genetic epidemiology of subclinical cardiovascular disease in the diabetes heart study. Ann Hum Genet. 2008; 72:598-610. [PubMed: 18460048] 
CARR JJ, CROUSE JR 3RD, GOFF DC JR, D'AGOSTINO RB JR, PETERSON NP, BURKE GL. Evaluation of subsecond gated helical CT for quantification of coronary artery calcium and comparison with electron beam CT. AJR Am J Roentgenol. 2000; 174:915-21. [PubMed: 10749222]

CARR JJ, NELSON JC, WONG ND, MCNITT-GRAY M, ARAD Y, JACOBS DR JR, SIDNEY S, BILD DE, WILLIAMS OD, DETRANO RC. Calcified coronary artery plaque measurement with cardiac CT in population-based studies: standardized protocol of Multi-Ethnic Study of Atherosclerosis (MESA) and Coronary Artery Risk Development in Young Adults (CARDIA) study. Radiology. 2005; 234:35-43. [PubMed: 15618373]

COKER, LH.; WAGENKNECHT, LE. Neurology. United States: 2011. Advanced glycation end products, diabetes, and the brain.

DE COURTEN B, DE COURTEN MP, SCHALKWIJK CG, WALKER KZ, FORBES J. Dietary Advanced Glycation End Products Consumption as a Direct Modulator of Insulin Sensitivity in Overweight Humans: A Study Protocol for a Double-Blind, Randomized, Two Period Cross-Over Trial. JMIR Res Protoc. 2015; 4:e93. [PubMed: 26223897]

DE VOS LC, MULDER DJ, SMIT AJ, DULLAART RP, KLEEFSTRA N, LIJFERING WM, KAMPHUISEN PW, ZEEBREGTS CJ, LEFRANDT JD. Skin autofluorescence is associated with 5 -year mortality and cardiovascular events in patients with peripheral artery disease. Arterioscler Thromb Vasc Biol. 2014; 34:933-8. [PubMed: 24526694]

FUKUSHIMA Y, DAIDA H, MORIMOTO T, KASAI T, MIYAUCHI K, YAMAGISHI S, TAKEUCHI M, HIRO T, KIMURA T, NAKAGAWA Y, YAMAGISHI M, OZAKI Y, MATSUZAKI M. Relationship between advanced glycation end products and plaque progression in patients with acute coronary syndrome: the JAPAN-ACS sub-study. Cardiovasc Diabetol. 2013; 12:5. [PubMed: 23289728]

GOLDIN A, BECKMAN JA, SCHMIDT AM, CREAGER MA. Advanced glycation end products: sparking the development of diabetic vascular injury. Circulation. 2006; 114:597-605. [PubMed: 16894049]

HANSSEN NM, BEULENS JW, VAN DIEREN S, SCHEIJEN JL, VAN DER AD, SPIJKERMAN AM, VAN DER SCHOUW YT, STEHOUWER CD, SCHALKWIJK CG. Plasma advanced glycation end products are associated with incident cardiovascular events in individuals with type 2 diabetes: a case-cohort study with a median follow-up of 10 years (EPIC-NL). Diabetes. 2015; 64:257-65. [PubMed: 24848072]

HANSSEN NM, ENGELEN L, FERREIRA I, SCHEIJEN JL, HUIJBERTS MS, VAN GREEVENBROEK MM, VAN DER KALLEN CJ, DEKKER JM, NIJPELS G, STEHOUWER CD, SCHALKWIJK CG. Plasma levels of advanced glycation endproducts Nepsilon(carboxymethyl)lysine, Nepsilon-(carboxyethyl)lysine, and pentosidine are not independently associated with cardiovascular disease in individuals with or without type 2 diabetes: the Hoorn and CODAM studies. J Clin Endocrinol Metab. 2013; 98:E1369-73. [PubMed: 23780372]

HEGAB Z, GIBBONS S, NEYSES L, MAMAS MA. Role of advanced glycation end products in cardiovascular disease. World J Cardiol. 2012; 4:90-102. [PubMed: 22558488]

HOUX PJ, JOLLES J, VREELING FW. Stroop interference: aging effects assessed with the Stroop Color-Word Test. Exp Aging Res. 1993; 19:209-24. [PubMed: 8223823]

HUGENSCHMIDT CE, HSU FC, HAYASAKA S, CARR JJ, FREEDMAN BI, NYENHUIS DL, WILLIAMSON JD, BOWDEN DW. The influence of subclinical cardiovascular disease and related risk factors on cognition in type 2 diabetes mellitus: The DHS-Mind study. J Diabetes Complications. 2013; 27:422-8. [PubMed: 23659774]

JIANG J, CHEN P, CHEN J, YU X, XIE D, MEI C, XIONG F, SHI W, ZHOU W, LIU X, SUN S, ZHANG P, YANG X, ZHANG Y, LIANG X, ZHANG Z, LIN Q, YU Y, MIYATA T, TIAN J, LIANG M, LUO W, XU X, HOU F. Accumulation of tissue advanced glycation end products correlated with glucose exposure dose and associated with cardiovascular morbidity in patients on peritoneal dialysis. Atherosclerosis. 2012; 224:187-94. [PubMed: 22857897]

JURANEK JK, KOTHARY P, MEHRA A, HAYS A, BRANNAGAN TH 3RD, SCHMIDT AM. Increased expression of the receptor for advanced glycation end-products in human peripheral neuropathies. Brain Behav. 2013; 3:701-9. [PubMed: 24363972] 
KALED A, AHMED SM, ISMAIL IKRAMS. Role of NE-(Carbxymethyl)Lysine in the Development of Ishemic Heart Disease in Type 2 Diabetes Mellitus. Journal of Clinical Biochemistry and Nutrition. 2007; 41:97-105. [PubMed: 18193103]

KELLOW NJ, SAVIGE GS. Dietary advanced glycation end-product restriction for the attenuation of insulin resistance, oxidative stress and endothelial dysfunction: a systematic review. Eur J Clin Nutr. 2013; 67:239-48. [PubMed: 23361161]

KILHOVD BK, BERG TJ, BIRKELAND KI, THORSBY P, HANSSEN KF. Serum levels of advanced glycation end products are increased in patients with type 2 diabetes and coronary heart disease. Diabetes Care. 1999; 22:1543-8. [PubMed: 10480523]

KIUCHI K, NEJIMA J, TAKANO T, OHTA M, HASHIMOTO H. Increased serum concentrations of advanced glycation end products: a marker of coronary artery disease activity in type 2 diabetic patients. Heart. 2001; 85:87-91. [PubMed: 11119472]

LANGE LA, BOWDEN DW, LANGEFELD CD, WAGENKNECHT LE, CARR JJ, RICH SS, RILEY WA, FREEDMAN BI. Heritability of carotid artery intima-medial thickness in type 2 diabetes. Stroke. 2002; 33:1876-81. [PubMed: 12105369]

LEURS P, LINDHOLM B. The AGE-RAGE pathway and its relation to cardiovascular disease in patients with chronic kidney disease. Arch Med Res. 2013; 44:601-10. [PubMed: 24231387]

LEZAK, MD.; HOWIESON, DB.; LORING, DW. Neuropsychological Assessment. New York: Oxford University Press; 2004.

LLAURADO G, CEPERUELO-MALLAFRE V, VILARDELL C, SIMO R, GIL P, CANO A, VENDRELL J, GONZALEZ-CLEMENTE JM. Advanced glycation end products are associated with arterial stiffness in type 1 diabetes. J Endocrinol. 2014; 221:405-13. [PubMed: 24681829]

LOPES-VIRELLA MF, HUNT KJ, BAKER NL, VIRELLA G, MORITZ T. The levels of MDA-LDL in circulating immune complexes predict myocardial infarction in the VADT study. Atherosclerosis. 2012; 224:526-31. [PubMed: 22963984]

MALDJIAN JA, LAURIENTI PJ, BURDETTE JH, KRAFT RA. Clinical implementation of spin-tag perfusion magnetic resonance imaging. J Comput Assist Tomogr. 2008; 32:403-6. [PubMed: 18520545]

MALDJIAN JA, WHITLOW CT, SAHA BN, KOTA G, VANDERGRIFF C, DAVENPORT EM, DIVERS J, FREEDMAN BI, BOWDEN DW. Automated white matter total lesion volume segmentation in diabetes. AJNR Am J Neuroradiol. 2013; 34:2265-70. [PubMed: 23868156]

MORAN C, MUNCH G, FORBES JM, BEARE R, BLIZZARD L, VENN AJ, PHAN TG, CHEN J, SRIKANTH V. Type 2 diabetes, skin autofluorescence, and brain atrophy. Diabetes. 2015; 64:279-83. [PubMed: 25053588]

NIN JW, JORSAL A, FERREIRA I, SCHALKWIJK CG, PRINS MH, PARVING HH, TARNOW L, ROSSING P, STEHOUWER CD. Higher plasma levels of advanced glycation end products are associated with incident cardiovascular disease and all-cause mortality in type 1 diabetes: a 12year follow-up study. Diabetes Care. 2011; 34:442-7. [PubMed: 21270199]

NOWOTNY K, JUNG T, HOHN A, WEBER D, GRUNE T. Advanced glycation end products and oxidative stress in type 2 diabetes mellitus. Biomolecules. 2015; 5:194-222. [PubMed: 25786107]

OKAMOTO T, YAMAGISHI S, INAGAKI Y, AMANO S, KOGA K, ABE R, TAKEUCHI M, OHNO S, YOSHIMURA A, MAKITA Z. Angiogenesis induced by advanced glycation end products and its prevention by cerivastatin. Faseb j. 2002; 16:1928-30. [PubMed: 12368225]

PIARULLI F, SARTORE G, LAPOLLA A. Glyco-oxidation and cardiovascular complications in type 2 diabetes: a clinical update. Acta Diabetol. 2012

RAFFIELD LM, COX AJ, HUGENSCHMIDT CE, FREEDMAN BI, LANGEFELD CD, WILLIAMSON JD, HSU F, MALDJIAN JA, BOWDEN DW. Heritability and genetic association analysis of neuroimaging measures in the Diabetes Heart Study. Neurobiol Aging. 2014

SCHMIDT P, GASER C, ARSIC M, BUCK D, FORSCHLER A, BERTHELE A, HOSHI M, ILG R, SCHMID VJ, ZIMMER C, HEMMER B, MUHLAU M. An automated tool for detection of FLAIR-hyperintense white-matter lesions in Multiple Sclerosis. Neuroimage. 2012; 59:3774-83. [PubMed: 22119648]

SCHOLTES VP, PEETERS W, VAN LAMMEREN GW, HOWARD DP, DE VRIES JP, DE BORST GJ, REDGRAVE JN, KEMPERMAN H, SCHALKWIJK CG, DEN RUIJTER HM, DE KLEIJN 
DP, MOLL FL, ROTHWELL PM, PASTERKAMP G. Type 2 diabetes is not associated with an altered plaque phenotype among patients undergoing carotid revascularization. A histological analysis of 1455 carotid plaques. Atherosclerosis. 2014; 235:418-23. [PubMed: 24937465]

SINGH R, BARDEN A, MORI T, BEILIN L. Advanced glycation end-products: a review. Diabetologia. 2001; 44:129-46. [PubMed: 11270668]

SINGH VP, BALI A, SINGH N, JAGGI AS. Advanced glycation end products and diabetic complications. Korean J Physiol Pharmacol. 2014; 18:1-14. [PubMed: 24634591]

SOURRIS KC, LYONS JG, DOUGHERTY SL, CHAND V, STRAZNICKY NE, SCHLAICH MP, GRIMA MT, COOPER ME, KINGWELL BA, DE COURTEN MP, FORBES JM, DE COURTEN B. Plasma advanced glycation end products (AGEs) and NF-kappaB activity are independent determinants of diastolic and pulse pressure. Clin Chem Lab Med. 2014; 52:129-38. [PubMed: 23525877]

SPAUWEN PJ, VAN EUPEN MG, KOHLER S, STEHOUWER CD, VERHEY FR, VAN DER KALLEN CJ, SEP SJ, KOSTER A, SCHAPER NC, DAGNELIE PC, SCHALKWIJK CG, SCHRAM MT, VAN BOXTEL MP. Associations of advanced glycation end-products with cognitive functions in individuals with and without type 2 diabetes: the maastricht study. J Clin Endocrinol Metab. 2015; 100:951-60. [PubMed: 25459912]

SRIKANTH V, WESTCOTT B, FORBES J, PHAN TG, BEARE R, VENN A, PEARSON S, GREENAWAY T, PARAMESWARAN V, MUNCH G. Methylglyoxal, cognitive function and cerebral atrophy in older people. J Gerontol A Biol Sci Med Sci. 2013; 68:68-73. [PubMed: 22496536]

STRAUSS, E.; SHERMAN, EMS.; SPREEN, O. A Compendium of Neuropsychological Tests: Administration, Norms, and Commentary. New York: Oxford University Press; 2006.

TEICHERT T, HELLWIG A, PESSLER A, HELLWIG M, VOSSOUGHI M, SUGIRI D, VIERKOTTER A, SCHULTE T, FREUND J, RODEN M, HOFFMANN B, SCHIKOWSKI T, LUCKHAUS C, KRAMER U, HENLE T, HERDER C. Association between Advanced Glycation End Products and Impaired Fasting Glucose: Results from the SALIA Study. PLoS One. 2015; 10:e0128293. [PubMed: 26018950]

TENG EL, CHUI HC. The Modified Mini-Mental State (3MS) examination. J Clin Psychiatry. 1987; 48:314-8. [PubMed: 3611032]

THOMAS MC, BAYNES JW, THORPE SR, COOPER ME. The role of AGEs and AGE inhibitors in diabetic cardiovascular disease. Curr Drug Targets. 2005; 6:453-74. [PubMed: 16026265]

THOMAS MC, WOODWARD M, NEAL B, LI Q, PICKERING R, MARRE M, WILLIAMS B, PERKOVIC V, COOPER ME, ZOUNGAS S, CHALMERS J, HILLIS GS. The Relationship Between Levels of Advanced Glycation End-Products and Their Soluble Receptor and Adverse Outcomes in Adults With Type 2 Diabetes. Diabetes Care. 2015

TURK Z, MESIC R, BENKO B. Comparison of advanced glycation endproducts on haemoglobin (Hb-AGE) and haemoglobin A1c for the assessment of diabetic control. Clin Chim Acta. 1998; 277:159-70. [PubMed: 9853699]

VAN EUPEN MG, SCHRAM MT, COLHOUN HM, HANSSEN NM, NIESSEN HW, TARNOW L, PARVING HH, ROSSING P, STEHOUWER CD, SCHALKWIJK CG. The methylglyoxalderived AGE tetrahydropyrimidine is increased in plasma of individuals with type 1 diabetes mellitus and in atherosclerotic lesions and is associated with sVCAM-1. Diabetologia. 2013; 56:1845-55. [PubMed: 23620061]

WAGENKNECHT LE, BOWDEN DW, CARR JJ, LANGEFELD CD, FREEDMAN BI, RICH SS. Familial aggregation of coronary artery calcium in families with type 2 diabetes. Diabetes. 2001; 50:861-6. [PubMed: 11289053]

WECHSLER, D. Manual for the Wechsler Adult Intelligence Scale-Revised. New York: Psychological Corporation; 1981.

YAFFE K, FALVEY C, HAMILTON N, SCHWARTZ AV, SIMONSICK EM, SATTERFIELD S, CAULEY JA, ROSANO C, LAUNER LJ, STROTMEYER ES, HARRIS TB. Diabetes, glucose control, and 9-year cognitive decline among older adults without dementia. Arch Neurol. 2012; 69:1170-5. [PubMed: 22710333] 
YAFFE K, LINDQUIST K, SCHWARTZ AV, VITARTAS C, VITTINGHOFF E, SATTERFIELD S, SIMONSICK EM, LAUNER L, ROSANO C, CAULEY JA, HARRIS T. Advanced glycation end product level, diabetes, and accelerated cognitive aging. Neurology. 2011; 77:1351-6. [PubMed: 21900628]

YAMAGISHI S, NAKAMURA K, MATSUI T, SATO T, TAKEUCHI M. Potential utility of statins, 3-hydroxy-3-methylglutaryl coenzyme A reductase inhibitors in diabetic retinopathy. Med Hypotheses. 2006; 66:1019-21. [PubMed: 16188392]

YU JY, AN XF, LIU JS, TEN SC, WANG X, ZHAO Y, HUANG S, GU WJ, GAO F. Plasma sRAGE is not associated with urinary microalbumin excretion in type 2 diabetic nephropathy at the early stage. Diabetes Res Clin Pract. 2010; 87:157-60. [PubMed: 19945761] 


\section{Highlights}

- Advanced glycation end products (AGEs) were associated with estimated glomerular filtration rate and coronary artery calcification in the entire cohort

- AGEs were not associated with any measures in the T2D-only analysis

- AGEs were associated with higher BMI in controls

- AGEs were associated with increased low density lipoproteins and triglycerides in controls

- AGEs were associated with reduced carotid artery calcification in controls

- AGEs were associated with reduced estimated glomerular filtration rate in controls

- AGEs were associated with lower digit symbol substitution test scores in controls

- AGEs were associated with lower grey matter volume in controls 
Table 1

Demographic Characteristics of DHS and DHS Mind Samples

\begin{tabular}{|c|c|c|c|}
\hline & All & DHS & DHS MIND \\
\hline $\mathrm{N}$ & 816 & 504 & 312 \\
\hline AGEs & $40.9 \pm 19.1$ & $40.7 \pm 20.2$ & $41.2 \pm 17.0$ \\
\hline \multicolumn{4}{|l|}{ Basic Demographics } \\
\hline Age (years) & $66.0 \pm 9.9$ & $67.7 \pm 8.9$ & $63.1 \pm 10.6$ \\
\hline N Female (\%) & $436(53.4)$ & $279(54.8)$ & $157(48.9)$ \\
\hline BMI $\left(\mathrm{kg} / \mathrm{m}^{2}\right)$ & $32.6 \pm 6.8$ & $31.5 \pm 6.6$ & $34.2 \pm 6.9$ \\
\hline History of Smoking (\%) & $436(53.4)$ & $275(48.1)$ & $161(50.2)$ \\
\hline \multicolumn{4}{|l|}{ Type 2 Diabetes } \\
\hline Affected (\%) & $709(86.9)$ & $399(69.8)$ & $310(96.6)$ \\
\hline Duration (years) & $15.3 \pm 7.7$ & $16.6 \pm 6.6$ & $13.7 \pm 8.7$ \\
\hline Fasting Glucose (mg/dL) & $141.5 \pm 54.6$ & $134.0 \pm 49.6$ & $153.7 \pm 59.9$ \\
\hline HbA1c $(\%)$ & $7.30 \pm 1.44$ & $7.12 \pm 1.34$ & $7.59 \pm 1.57$ \\
\hline \multicolumn{4}{|l|}{ Subclinical CVD and Kidney Function Measures } \\
\hline Prior History of CVD (\%) & $278(34.1)$ & $164(28.7)$ & $114(35.5)$ \\
\hline Pulse Pressure (mmHg) & $58.4 \pm 6.5$ & $61.1 \pm 16.1$ & $54.1 \pm 16.3$ \\
\hline Hypertension (\%) & $703(86.2)$ & $438(76.6)$ & $265(82.6)$ \\
\hline Coronary artery calcified plaque & $1101 \pm 2140$ & $1245 \pm 2215$ & - \\
\hline Carotid artery calcified plaque & $226 \pm 597$ & $252 \pm 626$ & - \\
\hline Infra-renal abdominal aortic calcified plaque & $7922 \pm 11912$ & $8648 \pm 12139$ & - \\
\hline Carotid intima-media thickness (mm) & $0.66 \pm 0.13$ & $0.67 \pm 0.13$ & - \\
\hline $\mathrm{eGFR}\left(\mathrm{ml} / \mathrm{min} / 1.73 \mathrm{~m}^{2}\right)$ & $69.2 \pm 19.6$ & $69.5(20.5)$ & - \\
\hline Albumin/Creatinine Ratio (mg/g) & $77.4 \pm 465.7$ & $77.4 \pm 465.7$ & - \\
\hline \multicolumn{4}{|l|}{ Lipids } \\
\hline Cholesterol (mg/dL) & $183.1 \pm 46.0$ & $180.1 \pm 47.9$ & - \\
\hline $\mathrm{HDL}(\mathrm{mg} / \mathrm{dL})$ & $42.9 \pm 12.6$ & $41.5 \pm 12.2$ & - \\
\hline LDL (mg/dL) & $102.9 \pm 34.4$ & $99.5 \pm 34.7$ & - \\
\hline Triglycerides (mg/dL) & $189.7 \pm 131.3$ & $198.8 \pm 142.2$ & - \\
\hline \multicolumn{4}{|l|}{ Educational Attainment } \\
\hline Education < High School Diploma (\%) & $116(14.3)$ & $87(17.3)$ & $29(9.4)$ \\
\hline Education High School Diploma (\%) & $382(47.1)$ & $270(53.8)$ & $112(36.2)$ \\
\hline Education > High School Diploma (\%) & $313(38.6)$ & $145(28.9)$ & $168(54.4)$ \\
\hline \multicolumn{4}{|l|}{ Cognitive Battery } \\
\hline Phonemic Fluency & $29.9 \pm 11.8$ & $28.7 \pm 11.7$ & $31.7 \pm 11.7$ \\
\hline
\end{tabular}




\begin{tabular}{lccc}
\hline & All & DHS & DHS MIND \\
\hline Semantic Fluency & $31.0 \pm 8.5$ & $29.9 \pm 8.0$ & $32.9 \pm 9.0$ \\
Modified Mini-Mental State & $91.2 \pm 6.9$ & $90.6 \pm 7.1$ & $92.2 \pm 6.4$ \\
Stroop & $34.0 \pm 19.4$ & $35.9 \pm 20.3$ & $31.0 \pm 17.6$ \\
Digit symbol substitution test & $50.4 \pm 16.0$ & $47.7 \pm 15.2$ & $54.8 \pm 16.3$ \\
Rey Auditory Verbal Learning Test & $41.2 \pm 10.2$ & $41.5 \pm 10.3$ & $40.6 \pm 10.0$ \\
\hline Neuroimaging & & & \\
\hline Total Grey Matter Volume & & & $535.9 \pm 57.4$ \\
Total White Matter Volume & $518.1 \pm 55.7$ & $508.3 \pm 52.2$ & $567.0 \pm 68.6$ \\
Total Brain Volume & $572.3 \pm 55.7$ & $575.2 \pm 72.7$ & $1102.6 \pm 111.7$ \\
White Matter Lesion Volume & $1090.3 \pm 144.5$ & $1083.5 \pm 115.6$ & $5.2 \pm 10.7$ \\
White Matter Fractional Anisotropy & $4.8 \pm 8.6$ & $4.6 \pm 7.0$ & $0.33 \pm 0.03$ \\
Grey Matter Fractional Anisotropy & $0.35 \pm 0.02$ & $0.36 \pm 0.02$ & $0.18 \pm 0.03$ \\
White Matter Mean Diffusivity & $0.20 \pm 0.02$ & $0.21 \pm 0.02$ & $0.80 \pm 0.5$ \\
Grey Matter Mean Diffusivity & $0.80 \pm 0.04$ & $0.80 \pm 0.04$ & $1.09 \pm 0.09$ \\
Cerebral Blood Flow & $1.10 \pm 0.09$ & $10 \pm 0.08$ & $39.7 \pm 14.8$ \\
\hline
\end{tabular}

Data shown are mean \pm SD, unless specified otherwise. AGEs - advanced glycation end products, BMI - Body Mass Index, eGFR - estimated glomerular filtration rate, HbA1c - glycated hemoglobin, HDL - High Density Lipoprotein cholesterol, LDL - Low Density Lipoprotein cholesterol. Bold indicates statistical significance. 


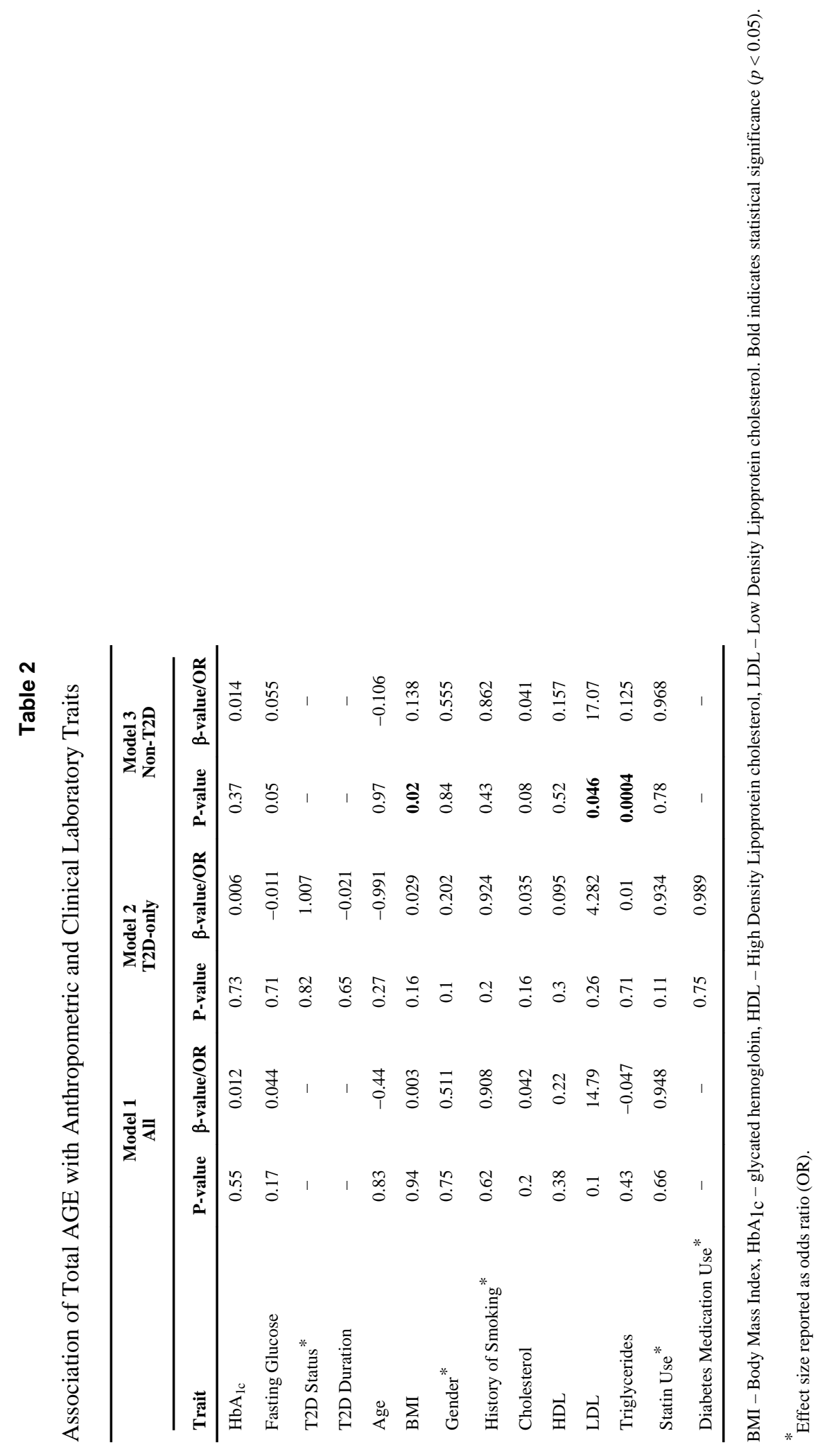




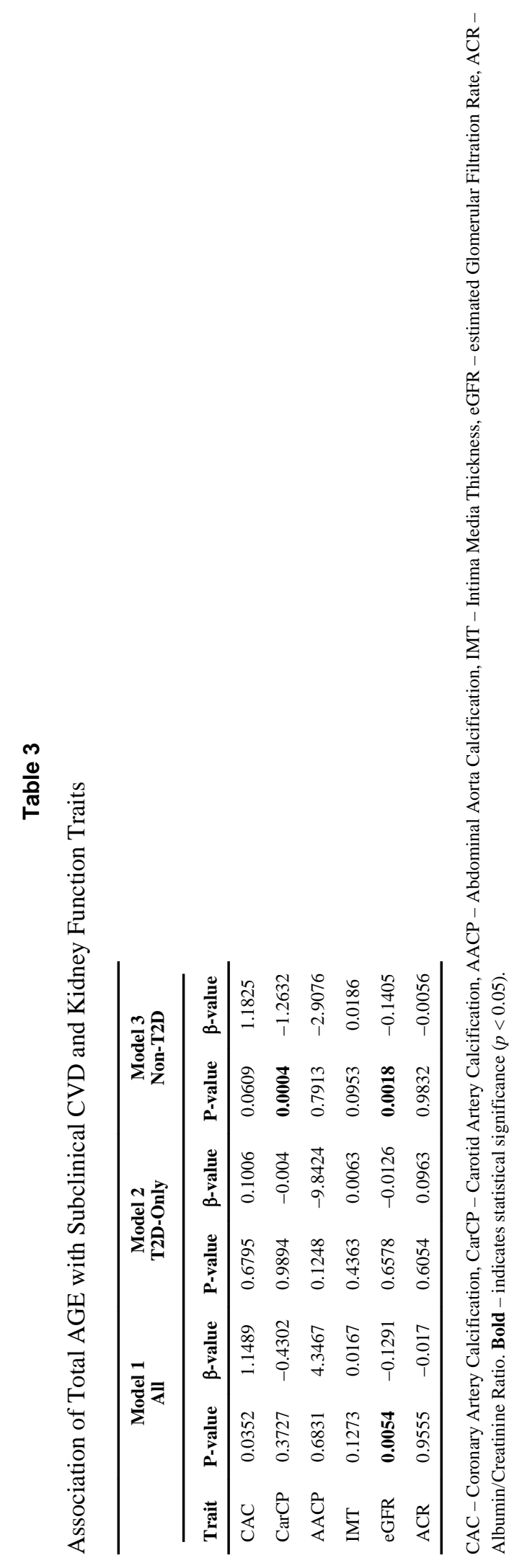




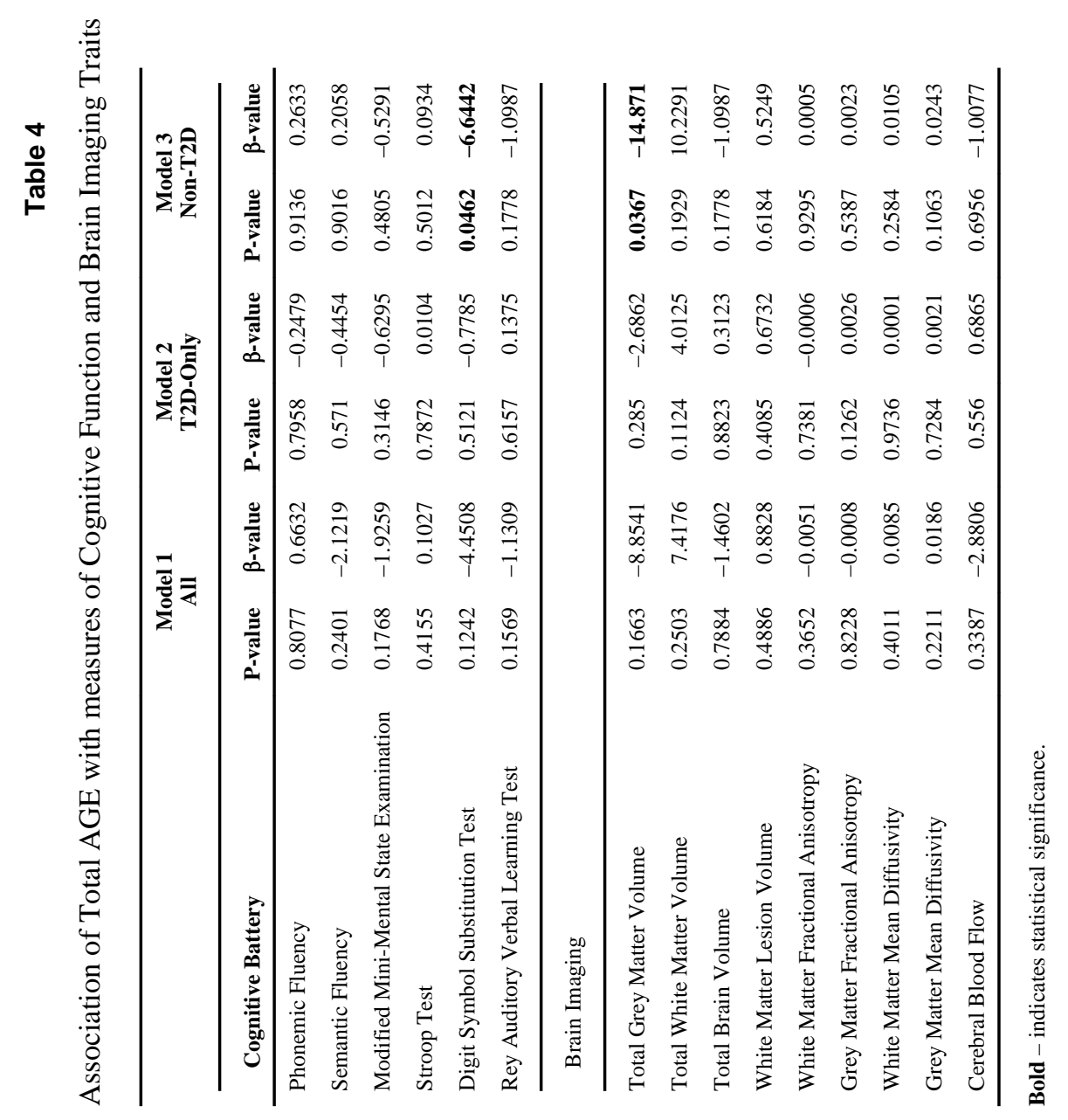

